\title{
ANALISIS DAERAH RAWAN BENCANA TANAH LONGSOR BERDASARKAN ZONA WATER CONTENT DI DESA OLAK ALEN KECAMATAN SELOREJO, BLITAR
}

\author{
Maulidah Aisyah, Widya Utama, Wien Lestari \\ Teknik Geofisika, Fakultas Teknik Sipil dan Perencanaan, Institut Teknologi Sepuluh Nopember \\ aisyahhbb@gmail.com
}

\begin{abstract}
Abstrak. Salah satu penyebab terjadinya tanah longsor yaitu adanya zona water content atau zona tersaturasi air dimana terdapat kondisi terakumulasinya air pada suatu lapisan tanah yang sukar meloloskan air. Kondisi tersebut dapat diketahui dengan metode geolistrik resistivitas dengan konfigurasi Wenner-Schlumberger karena dapat menerjemahkan kondisi bawah permukaan secara horizontal maupun lateral dengan baik berdasarkan nilai resistivitas. Nilai zona water content yang terlihat yaitu antara 4,39-9,29 $\Omega \mathrm{m}$. Berdasarkan peta rawan bencana yang telah dibuat, faktor penyebab terjadinya tanah longsor adalah curah hujan, tutupan lahan, dan kelerengan. Hasil pemetaan yang telah dilakukan menunjukkan bahwa Kecamatan Selorejo merupakan salah satu daerah yang kerawanan longsornya bernilai sedang, yakni diantara 24,03.

Kata Kunci- Tanah longsor, Zona Water content, Geolistrik
\end{abstract}

Abstract. One of the causes of landslides is water saturated zone where there is a condition of accumulation of water that trapped in impermeable soil. This can be known by using the resistivity method with the Wenner-Schlumberger configuration that can figure the subsurface condition both horizontally and laterally well base on resistivity parameter. The water content zone values are seen between 4.39 $9.29 \Omega \mathrm{m}$. Another causes from landslide is also seen in the maps that writer have been made such as rainfall, land cover, and slopes. The map that has been done shows that Selorejo District is one of the areas that have moderate vulnerability, is around 24.03

Keywords: Landslide, Resistivity, Water content Zone.

\section{PENDAHULUAN}

Gerakan tanah merupakan salah satu proses geologi yang terjadi akibat interkasi beberapa kondisi antara lain geomorfologi, struktur geologi, hidrogeologi dan tata guna lahan. Kondisi yang saling berpengaruh tersebut dapat mewujudkan kondisi lereng yang cenderung bergerak (Karnawati, 2005). Pergerakan tanah dapat diketahui dengan tanda-tanda seperti munculnya retak tarik dan kerutan di permukaan lereng, miringnya pepohonan, hilangnya kelurusan fondasi bangunan dan lainnya (Hardiyatmo, 2012).

Kabupaten Blitar merupakan salah satu kawasan di Jawa Timur dengan kondisi geologi berupa pegunungan vulkanik pada bagian utara dan bagian selatan merupakan dataran rendah. Dengan adanya kawasan pegunungan pada bagian utara inilah membuat Kabupaten Blitar termasuk dalam zona rentan pergerakan tanah. Salah satu Kecamatan yang rawan tanah longsor merupakan Kecamatan Selorejo dengan tingkat gerakan tanah menengah.
Salah satu cara untuk mengetahui daerah yang rawan longsor adalah dengan membuat peta rawan bencana longsor. Dari peta tersebut, kita dapat mengetahui daerah mana saja yang perlu dilakukan pencegahan bencana longsor. Tujuan dari penelitian ini adalah menentukan zona water content dengan metode resistivitas dan memetakan daerah rawan bencana tanah longsor dengan batasan daerah hanya di Desa Olak Alen Kecamatan Selorejo, Kabupaten Blitar dan menggunakan metode resistivitas konvigurasi Wenner-Schlumberger sebanyak 4 line.

\section{TINJAUAN PUSTAKA}

\section{Geologi Regional}

Daerah penelitian berada di Desa Olak Alen, Kecamatan Selorejo, Kabupaten Blitar. Daerah ini berada di Provinsi Jawa Timur yang secara regional geologi dibagi menjadid tujuh zona, dari utara ke selatan yaitu Zona Antiklinorium Rembang, Dataran Alluvial Jawa timur, Zona Randublatung, Zona 
Kendeng, Zona Depresi TengahJawa timur, Gunungapi Kuarter, dan Zona Pegunungan Selatan Jawa timur.

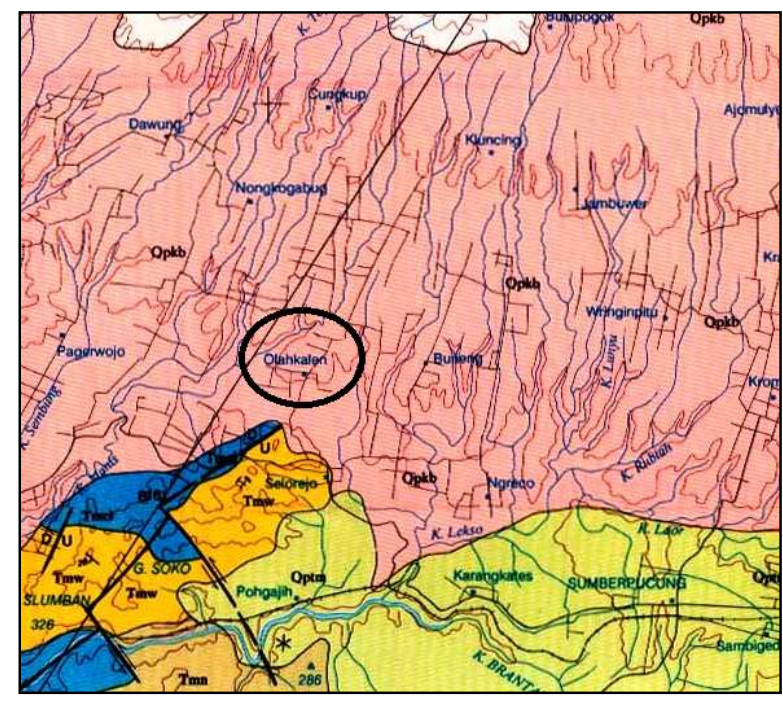

Gambar 1 Peta Geologi Daerah Penelitian

Daerah penelitian yang ditandai dengan lingkaran (lihat Gambar 1) termasuk dalam daerah yang dihasilkan dari batuan hasil letusan Gunung Butak dan juga batuan lepas hasil dari endapan sungai Brantas dengan kemiringan 0\%-20\%. Batuan penyusun daerah ini didominasi oleh breksi gunung api, tuff breksi, dan tuff pasiran.

\section{Klasifikasi Tingkat Bahaya Longsor}

Klasifikasi tingkat bahaya longsor dilakukan dengan cara menggabungkan dan melakukan pembobotan (scoring) dari parameter lereng, penggunaan lahan, jenis tanah, kerapatan vegetasi, dan curah hujan. Metode yang digunakan adalah tumpang susun atau dikenal dengan istilah overlay dari setiap parameter, maka perlu ada pemberian bobot dan skor/nilai total dari hasil bobot pada setiap parameter. Klasifikasi variabel lereng dan pembobotan masing-masing parameter mengacu pada indeks panjang dan kemiringan lereng dari Hammer (1980) yang digunakan pula oleh Dirjen BRLKT Departemen Kehutanan. Klasifikasi Jenis penggunaan lahan dalam kaitannya dengan bahaya longsor dibedakan menjadi 6 kelompok, yaitu: hutan, kebun campuran, perkebunan, sawah, tegalan, dan permukiman. Berikut pembobotan masing-masing parameter yang digunakan dalam penyusunan peta rawan longsor.

Tabel 1. Klasifikasi pembobotan parameter longsor.

\begin{tabular}{|l|l|}
\hline \multicolumn{1}{|c|}{ Parameter } & \multicolumn{1}{c|}{ Bobot } \\
\hline Kelerengan & 40 \\
\hline Curah Hujan & 30 \\
\hline Jenis Tanah & 20 \\
\hline Penggunaan Lahan & 10 \\
\hline
\end{tabular}

Tabel 2. Klasifikasi pembobotan parameter kelerengan

\begin{tabular}{|c|c|c|}
\hline $\begin{array}{l}\text { Parameter } \\
\text { Kelas Lereng } \\
\text { (\%) }\end{array}$ & $\begin{array}{l}\text { Nilai Bobot } \\
\text { (Harkat) }\end{array}$ & $\begin{array}{l}\text { Total Bobot } \\
\text { (Bobot*40) }\end{array}$ \\
\hline$>40$ & 0,45 & 18 \\
\hline $25-40$ & 0,32 & 12,8 \\
\hline $15-25$ & 0,15 & 6 \\
\hline $8-15$ & 0,07 & 2,8 \\
\hline $0-8$ & 0,02 & 0,8 \\
\hline
\end{tabular}

Tabel 3. Klasifikasi pembobotan curah hujan

\begin{tabular}{|l|l|l|l|}
\hline $\begin{array}{l}\text { Curah } \\
\text { Hujan }\end{array}$ & \multicolumn{1}{|c|}{ Kelas } & $\begin{array}{c}\text { Nilai } \\
\text { Bobot }\end{array}$ & $\begin{array}{c}\text { Total Bobot } \\
\text { (Bobot*30) }\end{array}$ \\
\hline $\begin{array}{l}>200 \\
\mathrm{~mm}\end{array}$ & Tinggi & 0,4 & 12 \\
\hline $\begin{array}{l}101- \\
200 \\
\mathrm{~mm}\end{array}$ & Sedang & 0,3 & 9 \\
\hline $\begin{array}{l}0-100 \\
\mathrm{~mm}\end{array}$ & Rendah & 0,2 & 6 \\
\hline
\end{tabular}

Tabel 4. Klasifikasi pembobotan parameter penggunaan lahan

\begin{tabular}{|l|l|l|}
\hline Erodibilitas & Nilai Bobot & $\begin{array}{l}\text { Total } \\
\text { Bobot } \\
\text { (Bobot*20) }\end{array}$ \\
\hline Tinggi & 0,4 & 8 \\
\hline Sedang & 0,3 & 6 \\
\hline Rendah & 0,2 & 4 \\
\hline
\end{tabular}

\section{Kumulatif Pembobotan Parameter}

Atas dasar pembobotan setiap parameter tersebut, maka didapatkan nilai total bobot yang digunakan sebagai acuan nilai/scoring mulai dari yang terendah sampai yang tertinggi seperti pada Tabel 5 berikut: 


\begin{tabular}{|c|c|c|c|c|c|}
\hline \multirow{2}{*}{$\begin{array}{c}\text { Akumulasi } \\
\text { Total } \\
\text { Bobot }\end{array}$} & \multicolumn{4}{|c|}{ Total Bobot } & \multirow{2}{*}{$\begin{array}{c}\text { Total Bobot } \\
\text { Akhir }\end{array}$} \\
\cline { 2 - 5 } & KI & PL & JT & CH & \\
\hline Terendah & 0,8 & 0,3 & 4 & 2 & 7,1 \\
\hline Tertiggi & 18 & 11,4 & 8 & 4 & 41,4 \\
\hline
\end{tabular}

Tingkat kerawanan longsor dibagi menjadi 5 kelas, yaitu:

1. Tidak Rawan: Total Bobot Akhir 7,10 - 13,96

2. Agak Rawan: Total Bobot Akhir 13,97-20,82

3. Cukup Rawan: Total Bobot Akhir 20,83-27,68

4. Rawan: Total Bobot Akhir 27,69 - 34,54

5. Sangat Rawan: Total Bobot Akhir 34,55-41,40

\section{METODOLOGI PENELITIAN}

Lokasi pengukuran di Desa Olak Alen, Kecamatan Selorejo, Blitar berjumlah empat lintasan menggunakan resistivitas konfigurasi WennerSchlumberger.

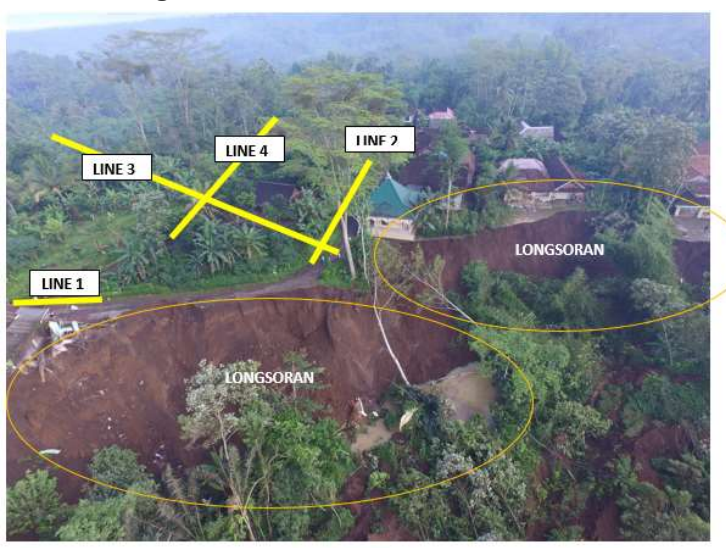

Gambar 2 Lokasi pengukuran dilakukan 4 line pada daerah sekitar longsor.

Setelah dilakukan proses pengumpulan data, kemudian diolah berdasarkan diagram alir sebagai berikut.

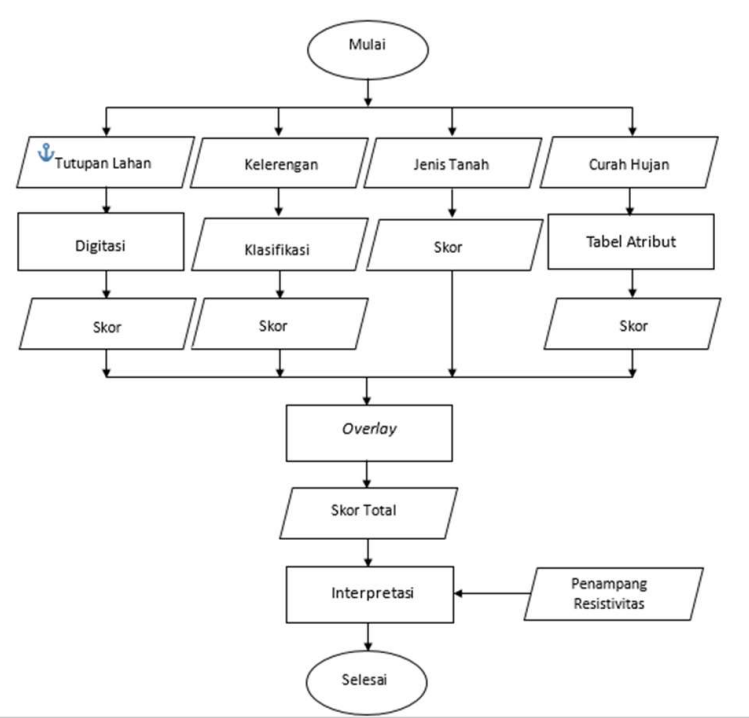

Gambar 3 Diagram Alir Pengolahan Data

\section{HASIL DAN PEMBAHASAN}

Analisis Korelasi Data Resistivitas dan Peta Rawan Bencana Tanah Longsor

Data hasil pengolahan resistivitas menunjukkan bahwa pada daerah penelitian terdapat zona water content dengan nilai resistivitas $4.39-9.39 \Omega \mathrm{m}$. Dari hasil pengolahan tersebut dapat diketahui jenis material yang ada dibawah permukaan sampai kedalaman 16 meter. Pada daerah pengukuran, jenis materialnya yaitu pasir kelanauan. Perbedaannya dapat dilihat dari nilai resistivitasnya, apabila nilai resistivitasnya semakin kecil maka dapat diasumsikan bahwa daerah tersebut memiliki material pasir. Hal ini didukung juga oleh penelitian (Utama dkk., 2016) tentang pengukuran geolistrik di daerah Olak Alen.

Data resistivitas diatas mendukung peta rawan bencana yang telah dibuat. Pada peta rawan bencana tanah longsor Kabupaten Blitar, daerah penelitian memiliki nilai kerawanan 24,04 yang berarti cukup rawan. 


\section{PETA RAWAN BENCANA TANAH LONGSOR KABUPATEN BLITAR}
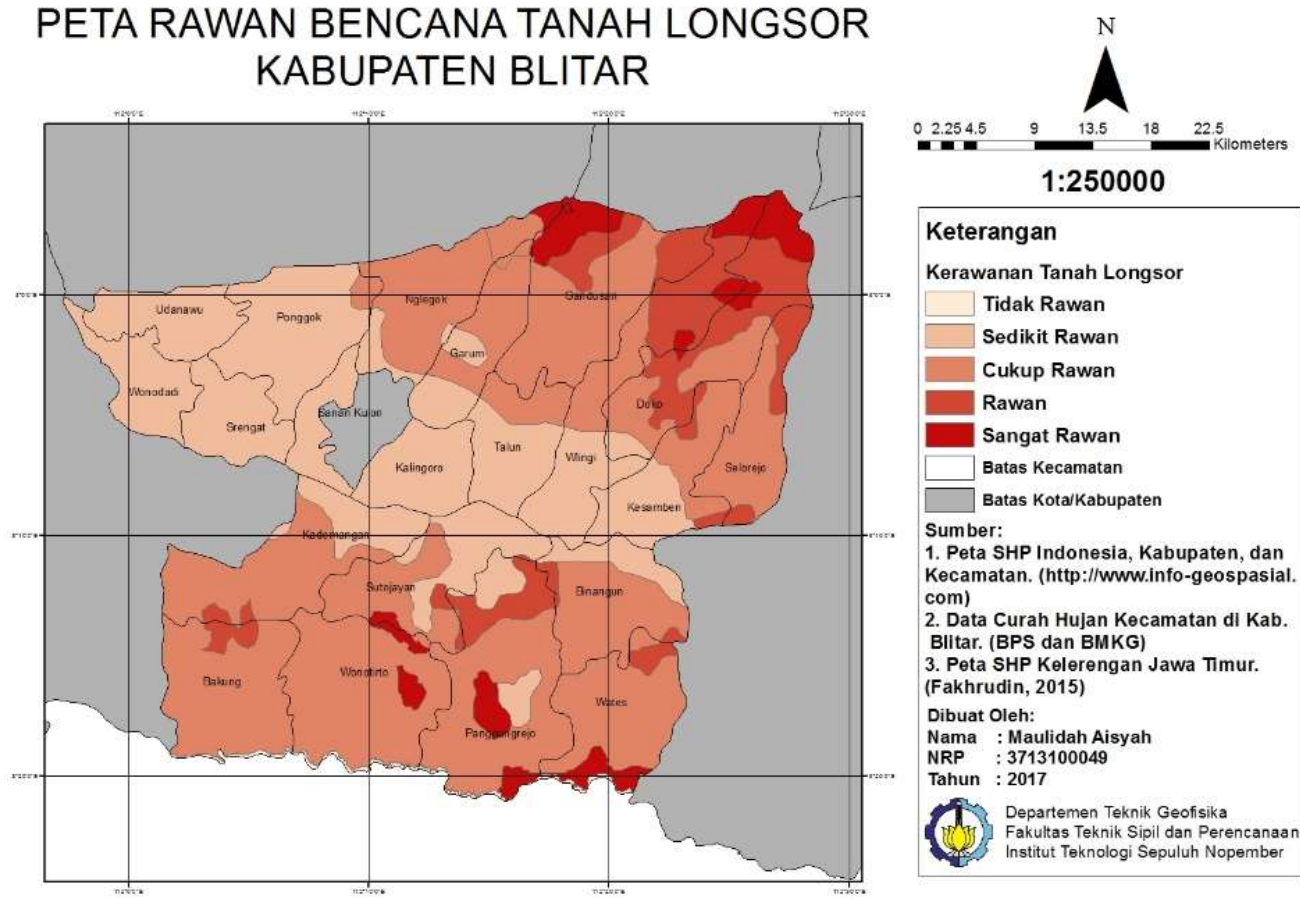

\section{Keterangan}

Kerawanan Tanah Longsor

\section{Tidak Rawan}

Sedikit Rawan

Cukup Rawan

Rawan

Sangat Rawan

Batas Kecamatan

Batas Kota/Kabupaten

Sumber:

1. Peta SHP Indonesia, Kabupaten, dan Kecamatan. (http://www.info-geospasial. com)

2. Data Curah Hujan Kecamatan di Kab. Blitar. (BPS dan BMKG)

3. Peta SHP Kelerengan Jawa Timur.

(Fakhrudin, 2015)

Dibuat Oleh:

Nama : Maulidah Aisyah

$\begin{array}{ll}\text { NRP } & : 37131000 \\ \text { Tahun } & : 2017\end{array}$

T. Departemen Teknik Geofisika Fakultas Teknik Sipil dan Perencanaa Institut Teknologi Sepuluh Nopember

Gambar 4 Peta Rawan Bencana Tanah Longsor Kabupaten Blitar

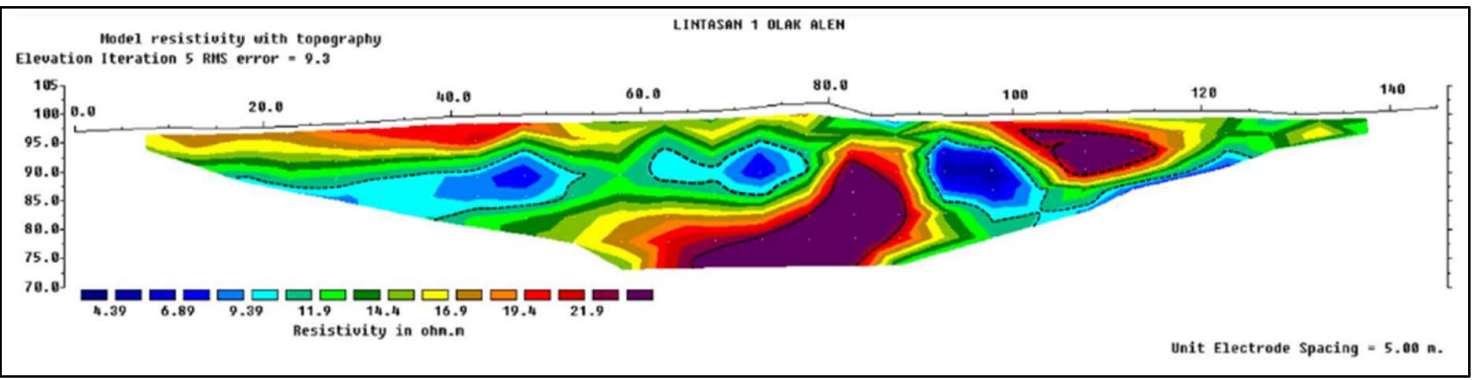

(a)

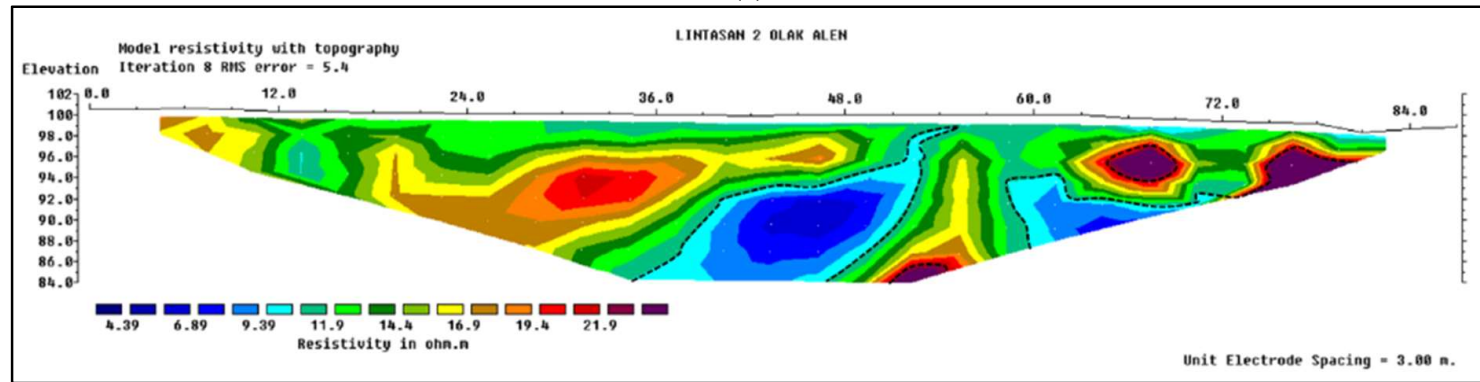

(b) 


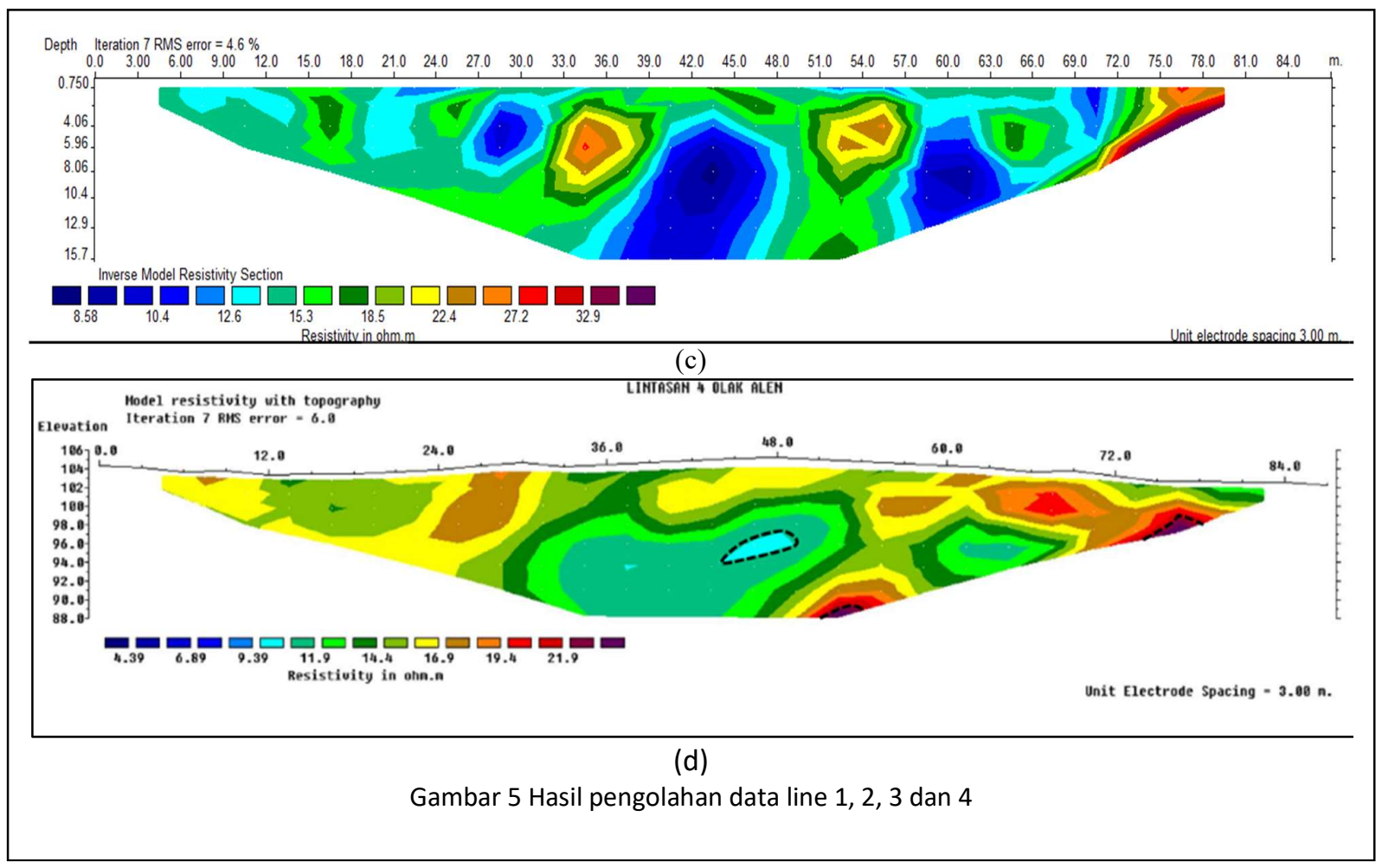

\section{PENUTUP}

\section{Kesimpulan}

Kesimpulan yang didapat dari penelitian ini adalah:

1. Nilai resistivitas $4,39-9,39 \Omega \mathrm{m}$ terdapat pada kedalaman 10-20 meter pada lintasan 1, 6-18 meter pada lintasan 2, 8-20 meter pada lintasan 3, dan 10-18 meter pada lintasan 4.

2. Zona water content terdapat pada kedalaman 10-20meter dengan nilai resistivitas 4,39-9,39 $\Omega \mathrm{m}$.

3. Berdasarkan peta rawan bencana tanah longsor, Kecamatan Selorejo merupakan daerah dengan tingkat kerawanan 24,04 yang berarti cukup rawan.

\section{Saran}

Saran yang dapat diberikan berdasarkan hasil dan kesimpulan untuk membangun hipotesa-hipotesa selanjutnya adalah:

1. Di Kabupaten Blitar terdapat beberapa kecamatan yang terindikasi rawan bencana tanah longsor, sehingga perlu dilakukan akuisisi data geolistrik resistivitas pada daerah rawan tersebut agar dapat dikorelasikan dengan peta rawan bencana tanah longsor.

2. Dari data tutupan lahan Kabupaten Blitar, jumlah penanaman vegetasi untuk membantu mencegah bencana tanah longsor masih kurang. Pemanfaatan lahanlahan yang memiliki kelerengan cukup tinggi masih berupa kebun yang bercampur dengan pemukiman dan sawah. Sebaiknya dimulai menanam tanaman yang berakar tunggang seperti sengon atau tanaman sejenis untuk menopang tanah yang berada di lereng yang curam.

3. Dilakukan monitoring disetiap daerah yang sudah terindikasi bencana tanah longsor dengan cara pemasangan sensor pergerakan tanah agar setiap gerakan tanah dapat terindikasi lebih dini dan ditangani dengan tepat. 


\section{Ucapan Terima Kasih}

Penulis mengucapkan terima kasih kepada dosen pembimbing Dr. Widya Utama dan Ibu Wien Lestari atas bimbingan dan pengarahan yang diberikan kepada penulis selama proses penelitian hingga penulisan.

\section{DAFTAR PUSTAKA}

Dwikorita Karnawati. 2005. Bencana Alam Gerak Massa Tanah di Indonesia dan Upaya Penanggulangannya. Yogyakarta: Universitas Gajah Mada

Hardiyatmo, H.C., 2012, Penanganan Tanah Longsor dan Erosi, Gadjah Mada University Press, Yogyakarta

Mochtar, Indrasurya B.2011. "Investigasi Longsoran Bagian Belakang Kantor Walikota Kota Bontang, Kalimantan Timur", Laporan Penyelidikan oleh Lembaga Penelitian dan Pengabdian kepada Masyarakat LPPM, ITS, untuk Pemda kota Bontang

Peta Geologi Indonesia lembar Blitar, 1992

Rahmawati, Arifah.2009.Pendugaan bidang gelincir tanah longsor berdasarkan sifat kelistrikan bumi dengan aplikasi geolistrik metode tahanan jenis konfigurasi schlumberger (Studi Kasus di Daerah Karangsambung dan Sekitarnya, Kabupaten Kebumen). Skripsi.Semarang : Fakultas FMIPA Unnes

Samudro, Arung, dkk. 2012. Pedoman Pembuatan Peta Rawan Longsor dan Banjir Bandang Akibat Runtuhnya Bendungan Alam. Kementrian Pekerjaan Umum.

Utama, W., R, J.P.G.N., Agustin, A.D., 2016. Identifikasi Letak dan Kedalaman Cracks pada Bidang Longsor Menggunakan Metode Resistivitas 2D Konfigurasi WennerSchlumberger Studi Kasus Kecamatan Selorejo, Blitar. J. Geosaintek 2, 195-200. 